\title{
The renin angiotensin system in liver and lung: impact and therapeutic potential in organ fibrosis
}

\begin{abstract}
Liver and lung fibrosis are two main organ diseases that are of particular importance in both Egypt and the US. Hepatitis C Virus "HCV" infection and idiopathic pulmonary fibrosis (IPF) are fibrotic diseases of the liver and lung respectively. The liver and lung are reported in literature to share many immune/inflammatory responses to damage through the lungliver axis. Most importantly, HCV was shown to enhance the development of IPF and is considered one of the risk factors for IPF. The renin angiotensin system (RAS) plays a critical role in the fibrogenesis and inflammation damage of many organs including liver and lung. The relatively recently identified component of RAS, angiotensin converting enzyme-2 (ACE-2), has shown a promising therapeutic potential in models of liver and pulmonary fibrosis. This article reviews the role of RAS in organ fibrosis with focus on role of ACE-2 in fibrotic diseases of the liver and the lung.
\end{abstract}

Keywords: renin angiotensin system, idiopathic pulmonary fibrosis, hepatitis $\mathrm{C}$ virus, bronchopulmonary dysplasia, angiotensin peptide, lung-liver axis
Review Article

Volume 5 Issue I - 2018

\author{
Amal Abdul-Hafez,' Tarek Mohamed,' \\ Hanan Omar, ${ }^{2}$ Mohamed Shemis, ${ }^{2}$ \\ Bruce D Uhal ${ }^{3}$ \\ 'Department of Pediatrics and Human Development, Michigan \\ State University, USA \\ ${ }^{2}$ Department of Biochemistry and Molecular Biology, Theodor \\ Bilharz Research Institute, Egypt \\ ${ }^{3}$ Department of Physiology, Michigan State University, USA
}

Correspondence: Bruce D Uhal, Department of Physiology, Michigan State University, 567 Wilson Rd, East Lansing, MI 48823, USA, Tel + I 517884 5131, Fax 5173555125 , Email uhal@msu.edu

Received: February 02, 2018 | Published: February 27, 2018
Abbreviations: RAS, renin angiotensin system; IPF, idiopathic pulmonary fibrosis; $\mathrm{HCV}$, hepatitis $\mathrm{C}$ virus; $\mathrm{BPD}$, bronchopulmonary dysplasia; ECM, extracellular matrix; ACE, angiotensin converting enzyme; ACE-2, angiotensin converting enzyme 2; Ang I, angiotensin I; Ang II, angiotensin II; Ang 1-7, angiotensin 1-7; AT1, angiotensin II receptor 1; AT2, angiotensin II receptor 2

\section{Introduction}

Diseases of liver and lung are of particular importance in both Egypt and the US. Hepatitis C (HCV) and schistosomiasis are major causes of liver fibrosis and cirrhosis in Egypt, ${ }^{1,2}$ while reported cases of acute viral hepatitis $\mathrm{C}$ infection increased more than 2.5 times in the US. ${ }^{3}$ Interestingly, HCV was shown to enhance the development of idiopathic pulmonary fibrosis (IPF) and is considered one of the risk factors for $\mathrm{IPF}^{4}$ Additionally, treatment of $\mathrm{HCV}$ with alpha interferon was shown to worsen IPF., 5 These facts support the need for a curative treatment of HCV-induced liver fibrosis and IPF different from currently available interferon-based therapy. Another fibroproliferative disease of the lung is bronchopulmonary dysplasia (BPD). BPD occurs in premature neonates with respiratory distress who require supplemental oxygen in the first days after birth. Occurrence of premature birth continues to rise in the $\mathrm{US}^{7}$ with about $20 \%$ of preterm infants diagnosed with BPD. ${ }^{8,9}$ BPD has become more common among Egyptian infants because of advances in care system. ${ }^{10}$

\section{Liver fibrosis and cirrhosis in hepatitis C}

Liver fibrosis is an increasing problem in the Egyptian population due to the spread of schistosomiasis and chronic hepatitis C. ${ }^{11}$ Hepatitis $\mathrm{C}$ virus (HCV) infection is a major medical challenge affecting around 200 million people worldwide. $\mathrm{HCV}$ is a major cause of chronic hepatitis, cirrhosis, and liver cancer occurring in up to $3 \%$ of the world's population. Parenteral exposure to HCV is the major mode of transmission of infection. Once established, infection will persist in up to $85 \%$ of individuals with only a minority of patients clearing viremia. ${ }^{12}$ Egypt has possibly the highest HCV prevalence in the world where $10 \%-20 \%$ of the general population is infected with $\mathrm{HCV} .{ }^{13}$ According to the Centers for Disease Control and Prevention (CDC), liver cirrhosis is the $4^{\text {th }}$ cause of death in Egypt with hepatitis being the $9^{\text {th }}$ cause. ${ }^{14}$ Direct healthcare costs of HCV-related disease exceed $\$ 700$ million annually and consume approximately $4.0 \%$ of the total health expenditure in Egypt, exemplifying the magnitude of the HCV epidemic in Egypt. ${ }^{15,16}$

In the US, reported cases of acute viral hepatitis $\mathrm{C}$ infection increased more than 2.5 times from 2010-2014. Based on new epidemiologic studies, at least 4.6 million persons are $\mathrm{HCV}$-antibody positive and approximately 3.5 million are currently infected with $\mathrm{HCV}^{3}$ This makes HCV infection the largest blood-borne viral epidemic in the USA, causing more deaths than HIV, and the leading cause of cirrhosis, liver cancer, liver failure, and deaths from liver disease. ${ }^{17,18}$ Treatment of HCV patients can prevent cirrhosis, liver failure, hepatocellular carcinoma, liver transplantation, and death, and can cure extra hepatic manifestations, relieve symptoms, and improve quality of life. ${ }^{19,20}$ This emphasizes the need to develop new treatment approach for HCV patients to prevent and reverse or at least attenuate liver fibrosis and cirrhosis. Most importantly, however, many patients with advanced liver disease and cirrhosis suffer from persistent liver injury even years after HCV cure. ${ }^{21,22}$

\section{Idiopathic pulmonary fibrosis}

Idiopathic pulmonary fibrosis (IPF) is the most commonly encountered interstitial lung disease. The published prevalence of IPF 
in various countries of the world has ranged from 0.7 per 100,000 in Taiwan to 63.0 per 100,000 in the United States, and the published incidence has ranged from 0.6 per 100,000 person/year to 17.4 per 100,000 person/year. ${ }^{23}$ A multicenter hospital-based case-control study was carried out in chest hospitals affiliated to three Egyptian cities (Cairo, Tanta and Mansoura) showed that some of the common occupations in Egypt are important risk factors for the development of IPF, including farming, raising birds and wood working. In this study, the risk of IPF in male workers was observed to increase significantly in chemical and petrochemical industries and carpentry and wood working, and with occupational exposures to wood dust and wood preservatives. Among female workers, a significant increase was observed in farming, raising birds and occupational exposures to animal feeds, products and dusts and pesticides. ${ }^{24}$

In the United States, the annual medical cost to the U.S. health care system for IPF patients is estimated at close to \$2 billion, excluding medication costs, as patients with IPF have an $82 \%$ higher risk of hospitalization. ${ }^{25}$ IPF is characterized by progressive accumulation of scar tissue in the lung and is associated with a median life expectancy of 2-5 years. Treatment options for IPF are limited, focusing on ineffective anti-inflammatory therapy, palliation, transplant or trial recruitment. ${ }^{26}$ Despite the ongoing research for the development of new antifibrotic drugs, there is no definitive cure yet for this devastating disease.

\section{Bronchopulmonary dysplasia}

Bronchopulmonary Dysplasia (BPD) occurs in premature neonates with respiratory distress who require supplemental oxygen in the first days after birth. BPD is recognized as a chronic lung disease of infancy that presents as a systemic syndrome and is associated with neurodevelopmental deficits, cerebral palsy, cognitive impairments, failure to thrive, corpulmonale, and pulmonary hypertension. ${ }^{27}$ High rates of in utero and perinatal exposure to infection may be causally related to preterm delivery and subsequent lung injury. ${ }^{28}$ Over the past 2 decades, the histological presentation of BPD has changed from heterogeneous pulmonary inflammation and fibrosis to uniform arrest of alveolar development and variable interstitial cellularity and/or fibroproliferation. ${ }^{29,30}$

Occurrence of premature birth continues to rise in the US (12$13 \%$ ), and preterm infants are at high risk for long-term medical impairments, including BPD and chronic lung disease of infancy. ${ }^{9}$ Many premature newborns require treatment in a neonatal intensive care unit at an annual national cost that exceeds $\$ 4$ billion, ${ }^{31}$ with estimated overall costs of treating babies with BPD to be $\$ 2.4$ billion. This amount is second only to the costs for treating asthma and far exceeds the costs for treating cystic fibrosis..$^{32} \mathrm{BPD}$ is also considered the single costliest complication of hospitalization among preterm infants, with an average cost per discharge of $\$ 116,000 .{ }^{33}$ Despite many advances in neonatal ventilation techniques, widespread use of surfactant and antenatal corticosteroids, the incidence of BPD has remained the same ${ }^{34}$ or even increased slightly. ${ }^{35,36}$

BPD has become more common among Egyptian infants because of advances in care and changes in the gestational age of premature infants. The lack of uniformity in the diagnostic criteria of BPD may be responsible for some of the reported variation. ${ }^{10}$ There is even higher incidence of Respiratory Distress Syndrome (up to $80 \%$ ) is seen in preterm infants with very low birth weight in BPD studies on the Egyptian population because of surfactant delay due to limited healthcare resources. ${ }^{10,37}$ BPD is associated with significant pulmonary and neurodevelopmental sequelae that continue to have health consequences into adulthood. ${ }^{35,38,39}$ Home oxygen therapy averages 92 days, when required and up to $50 \%$ of babies with BPD require readmission to the hospital for lower respiratory tract illness in the first year of life. This necessitates developing new approaches for BPD prevention and treatment.

\section{Liver and lung fibrosis}

The liver and lung are reported in literature to share many general responses to damage involving oxidative stress and altered extracellular matrix (ECM) deposition in what is called the lung-liver axis. Additionally, both organs possess resident macrophages that play key roles in mediating the immune/inflammatory response..$^{40-43}$ Idiopathic pulmonary fibrosis (IPF) is a possible autoimmune manifestation of $\mathrm{HCV}$ infection. ${ }^{4,44}$ A number of studies have suggested an association between IPF and viruses such as hepatitis $C .{ }^{45}$ However, there is still some ambiguity with respect to the association between HCV infection and IPF. ${ }^{46}$ The following lines of evidence would provide varying degrees of support for a pathogenetic link between HCV infection and IPF. First, there is a higher frequency of $\mathrm{HCV}$ markers in IPF patients such as anti-HCV antibodies, increased prevalence of HCV infection and viral replication $(13.3 \%$ vs. $0.3 \%$ in control group) ${ }^{47}$ second, there is an increased count of lymphocytes and neutrophils in bronchoalveolar lavage fluid in patients with HCV chronic infection. ${ }^{48,49}$ Third, the frequency of pulmonary fibrosis was higher in patients with cryoglobulinemia related to HCV than in cryoglobulin-negative patients. ${ }^{50}$ It is suggested that pulmonary fibrosis in HCV-related cryoglobulinemia is triggered by vascular deposition of circulating HCV-containing immune complexes. ${ }^{51}$ Furthermore, sometimes IPF is aggravated or manifest after treatment with alpha interferon, the standard therapy for chronic hepatitis C. ${ }^{5,6,52}$

\section{Renin angiotensin system in fibrosis}

The renin angiotensin system (RAS) (Figure 1) has been traditionally viewed as an endocrine system "Endocrine RAS" playing a significant role in blood pressure regulation. In the endocrine RAS, the kidney produced enzyme renin acts on circulating AGT protein. Renin cleaves AGT to produce a fragment of 10 amino acids known as angiotensin I (Ang I). Ang I is converted by angiotensin-converting enzyme (ACE) to the active octapeptideAng II that exerts its actions through binding to specific cell surface angiotensin receptors. Two main receptors to Ang II have been identified; $\mathrm{AT}_{1}$ and $\mathrm{AT}_{2}$, both belong to superfamily of seven transmembrane G-protein coupled receptors. The $\mathrm{AT}_{1}$ receptor mediates all of the classical actions of Ang II (vasodilation, sodium retention, cell growth and proliferation), while $\mathrm{AT}_{2}$ receptor promotes vasodilation, cell differentiation, inhibition of cell growth and apoptosis and may play a counterbalancing role to the effects of Ang II on $\mathrm{AT}_{1}$ receptor. ${ }^{53}$ The angiotensin converting enzyme 2 (ACE-2) was shown to play a protective role in the fibrogenesis and inflammation of many organs including liver and lung. ${ }^{54,55} \mathrm{ACE}-2$ is a part of the renin angiotensin system (Figure 1). ACE-2 and its product angiotensin 1-7 (Ang 1-7) acting on mas oncogene receptor were identified more recently than the previously mentioned components of this system and are thought to have counteracting effects against 
the adverse actions of these other RAS components. Findings from numerous experimental studies have suggested notable protective effects in the cardiovascular system..$^{56}$

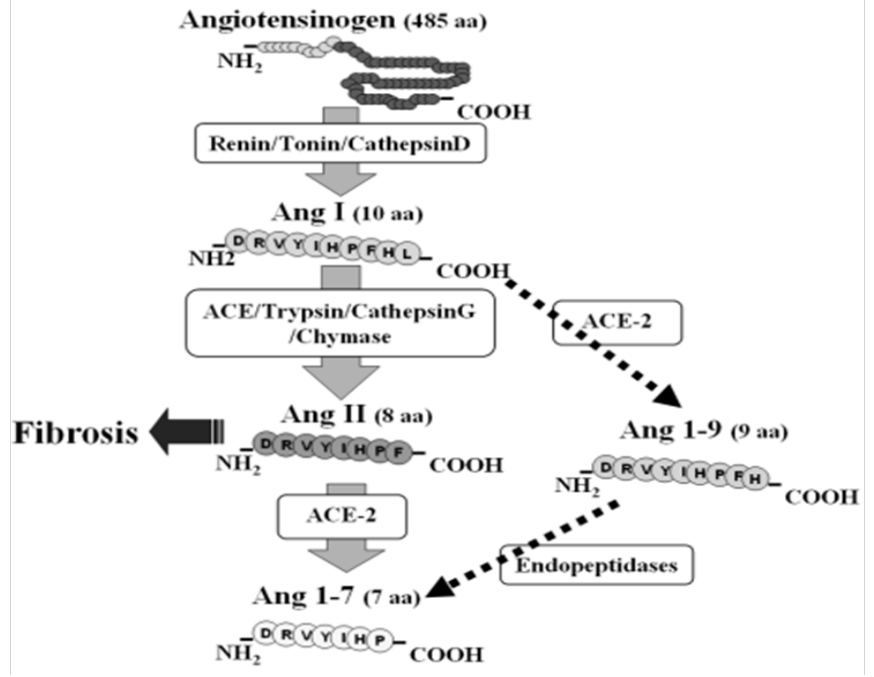

Figure I Renin Angiotensin System (RAS).

More recently, "Local RAS" has been identified in variety of tissues such as heart, kidney, liver, lung, brain, pancreas and adipose tissue, where RAS components expression has been detected. ${ }^{57,58}$ Local RAS is involved in injury, inflammatory and fibrogenic diseases of many organs including heart, ${ }^{59,60}$ lung, ${ }^{61,62}$ liver, ${ }^{63}$ pancreas $^{64}$ and kidneys ${ }^{65,66}$ by mechanisms independent of the blood-derived RAS.

\section{Angiotensin converting enzyme-2 (ACE-2) in fibrosis}

ACE-2 and its product Ang 1-7 were shown to play a protective role in experimental models of fibrosis. In cardiac fibrosis, ACE-2 expression was shown to be protective against angiotensin II-induced and hypertension-induced cardiac fibrosis. ${ }^{67}$ In liver fibrosis, both Ang 1-7 and ACE-2 provide protection against the development of liver injury and progression to cirrhosis. ${ }^{68}$ In experimental acute lung injury, ACE-2 also has protective effect associated with reduced levels of Ang II. Earlier studies of knockout mice have shown a clear protective effect of ACE-2 on experimental acute lung injury in response to acid aspiration or sepsis; the protective effect of ACE-2 was associated with reduced levels of Ang II after experimental lung injury. ${ }^{66} \mathrm{~A}$ study on rat brain astrocytes showed that Ang II down-regulates ACE-2 mRNA through angiotensin receptorI in a positive feed-forward system that favors Ang II - mediated responses ${ }^{69}$ In the lung models of fibrosis, ACE-2 was shown to regulate alveolar epithelial cell survival by balancing the proapoptoticAng II and its antiapoptotic degradation product Ang1-7 through its receptor "mas". ${ }^{4,70}$

\section{ACE-2 and liver fibrosis}

The role of ACE-2 in liver disease is of special interest as several lines of evidence suggest that the RAS also participates in the regulation of hepatic inflammation, tissue remodeling, and fibrosis after liver injury analogous to other organs. RAS induces key steps involved in hepatic fibrosis, such as activation of hepatic stellate cells and expression of transforming growth factor $\beta 1 .^{71}$ Treatment with angiotensin-converting enzyme inhibitors, and angiotensin receptor blockers attenuate fibrosis progression in both animal and human studies. $^{72}$ Additionally, supplementation of ACE-2 can prevent liver fibrosis of bile duct ligation mouse model. ${ }^{55,72}$

\section{ACE-2 and pulmonary fibrosis}

Similar to liver disease, ACE-2 has been shown to play an established protective role in lung disease through effects mediated by Mas oncogene, the ACE-2 peptide product ANG1-7 receptor. ${ }^{54,73-75}$ Previous studies from our lab and other groups suggest that ACE-2 is down-regulated in fibrotic conditions of the adult and neonatal human lung ${ }^{54,73,74}$ via Mas receptor mechanisms..$^{70}$ Data from our lab was first to discover the significant decrease of ACE-2 in the human IPF lung and identify the protective effects of ACE-2 in the IPF disease. ${ }^{54}$ We also demonstrated that ACE-2 regulates alveolar epithelial cell survival by balancing the proapoptotic Ang II and its antiapoptotic degradation product Ang 1-7 through the Ang 1-7 action on its receptor "mas". 70

The alveolar epithelial type II cells are considered lung alveolar "stem cells" ${ }^{76,77}$ They represent a major source of ACE-2 in the adult lung, are normally quiescent but actively proliferate in lung fibrosis due to lung injury and downregulate this protective enzyme. In our studies we found that in lung biopsy specimens obtained from IPF patients, immunoreactive ACE-2 was absent in alveolar epithelia that were positive for proliferation markers but was robustly expressed in alveolar epithelia devoid of proliferation markers. This explained the loss of ACE-2 in lung fibrosis and demonstrated cell cycle-dependent regulation of this protective enzyme. ${ }^{78}$

\section{ACE-2 and bronchopulmonary dysplasia}

Bronchopulmonary dysplasia (BPD) is recognized as a chronic lung disease of infancy that presents as a systemic syndrome and can be associated with neurodevelopmental deficits, cognitive impairments, failure to thrive, pulmonary hypertension and corpulmonale. ${ }^{27}$ Supplemental oxygen, which is frequently used in the treatment of pulmonary insufficiency in premature infants, has been implicated in the development of BPD. ${ }^{73,74}$ In adult animal models of acute lung injury, ${ }^{79,80}$ ACE-2 was shown to inhibit lung edema formation and inflammation as well as fibrogenesis. However, little is known about the role of ACE-2 in neonatal models of BPD. Our research group showed that ACE-2 is expressed in fetal human lung fibroblasts but is significantly decreased by hyperoxic gas lung injury, ${ }^{74}$ an effect reversed when hyperoxia preceded by hypoxia. ${ }^{73}$ Furthermore, Wagenaar et al. ${ }^{75}$ showed that Mas receptor agonists reduce inflammation of the oxygen-induced lung injury in rats. ${ }^{75}$

Chorioamnionitis and mechanical ventilation are also associated with bronchopulmonary dysplasia (BPD) in preterm infants. ${ }^{81,82} \mathrm{~A}$ study by Hillman et al., ${ }^{82}$ on neonatal lamb model of chorioamnionitis and infection showed altered ratio of ACE-1 to ACE-2. ${ }^{82}$ Although studied in adults, a recent pilot clinical trial of GSK2586881, a recombinant form of human angiotensin-converting enzyme 2 (rhACE-2) was performed in adults with acute respiratory distress syndrome. As a result of treatment there was a trend for a decrease in interleukin- 6 concentrations in rhACE-2-treated subjects compared with placebo. ${ }^{83}$ This shows potential use of ACE2 as a therapeutic for neonates as well.

\section{Conclusion}

Fibrotic diseases of the liver and the lung are of great healthcare concern and economic importance in both the US and Egypt. HCVinduced liver fibrosis, IPF, and BPD are fibrotic diseases of the liver and the lung in which a role for the RAS has been established. The increasing rate and incidence of $\mathrm{HCV}$ in both the US and Egypt 
necessitates exploring new treatment options for liver fibrosis. HCV is also considered a risk factor for IPF, the most common form of interstitial lung disease with no definite cure so far. This also mandates novel therapeutics exploration for IPF. Both the liver and lung share common responses to damage leading to disruption in the ECM and leading to organ fibrosis. The local RAS contains many molecules. The ACE/Ang II/AT axis of the system plays role in the development of fibrotic diseases, while the other counter components, ACE-2/Ang1-7/Mas axis, have shown potential protective effects in organ fibrosis. Treatment of liver and lung fibrosis by stimulating this protective arm of RAS would offer new therapeutic options.

Authors are shedding the light on the connection between and the importance of lung and liver fibrotic diseases. Futures studies are planned by authors to further understand role of RAS in lung and liver injury and suggest that RAS modification by using ACE- 2 might be a potential therapy to prevent/attenuate Lung and liver fibrosis/disease.

\section{Acknowledgements}

This work was conceived due to the collaboration between the authors' institutions in exchange visits. This work was supported by Michigan State University, USA, and Theodor Bilharz Research Institute, Egypt.

\section{Conflict of interest}

The authors do not have any conflict of interests.

\section{References}

1. Strickland GT. Liver disease in Egypt: Hepatitis C superseded schistosomiasis as a result of latrogenic and biological factors. Hepatology. 2006;43(5):915-922.

2. Van-Lume DS, Albuquerque Mde F, Souza AI, et al. Association between Schistosomiasis mansoni and hepatitis C: systematic review. Rev Saude Publica. 2013;47(2):414-424.

3. Edlin BR, Eckhardt BJ, Shu MA, et al. Toward a more accurate estimate of the prevalence of hepatitis $\mathrm{C}$ in the United States. Hepatology. 2015;62(5):1353-63.

4. Jadali Z, Alavian SM. Autoimmune Diseases Co-Existing with Hepatitis C Virus Infection. Iran J Allergy Asthma Immunol. 2010;9(4):191-206.

5. Chin K, Tabata C, Sataka N, et al. Pneumonitis associated with natural and recombinant interferon alfa therapy for chronic hepatitis C. Chest. 1994;105(3):939-41.

6. Slavenburg S, Heijdra YF, Drenth JP. Pneumonitis as a consequence of (peg) interferon-ribavirin combination therapy for hepatitis $\mathrm{C}$ : a review of the literature. Dig Dis Sci. 2010;55(3):579-85.

7. Goldenberg RL, Culhane JF, Iams JD, et al. Epidemiology and causes of preterm birth. Lancet. 2008;371(9606):75-84.

8. Walsh MC, Yao Q, Gettner P, et al. Impact of a physiologic definition on bronchopulmonary dysplasia rates. Pediatrics. 2004;114(5):1305-11.

9. Deakins KM. Bronchopulmonary dysplasia. Respir Care. 2009;54(9):1252-62.

10. Elhawary NA, Tayeb MT, Abdel-Ghafar S, et al. TNF-238 polymorphism may predict bronchopulmonary dysplasia among preterm infants in the Egyptian population. Pediatr Pulmonol. 2013;48(7):699-706.

11. El Ray A, Asselah T, Moucari R, et al. Insulin resistance: a major factor associated with significant liver fibrosis in Egyptian patients with genotype 4 chronic hepatitis C. Eur J Gastroenterol Hepatol. 2013;25(4):421-7.
12. El-Guindi MA. Hepatitis C Viral Infection in Children: Updated Review. Pediatr Gastroenterol Hepatol Nutr. 2016;19(2):83-95.

13. Houldsworth A. Exploring the possibility of arthropod transmission of HCV. J Med Virol. 2017;89(2):187-194.

14. http://www.cdc.gov/globalhealth/countries/egypt/

15. Estes C, Abdel-Kareem M, Abdel-Razek W, et al. Economic burden of hepatitis C in Egypt: the future impact of highly effective therapies. Aliment Pharmacol Ther. 2015;42(6):696-706.

16. http://data.worldbank.org/indicator/SH.XPD.TOTL.ZS

17. http://www.hevguidelines.org

18. Ly KN, Xing J, Klevens RM, et al. The Increasing Burden of Mortality From Viral Hepatitis in the United States Between 1999 and 2007. Ann Intern Med. 2012;156(4):271-8.

19. Smith-Palmer J, Cerri K, Valentine W. Achieving sustained virologic response in hepatitis $\mathrm{C}$ : a systematic review of the clinical, economic and quality of life benefits. BMC Infect Dis. 2015;15:19.

20. Edlin BR. Access to treatment for hepatitis $C$ virus infection: time to put patients first. Lancet Infect Dis. 2016;16(9):e196-201.

21. D'Ambrosio R, Aghemo A, Rumi MG, et al. A morphometric and immunohistochemical study to assess the benefit of a sustained virological response in hepatitis $\mathrm{C}$ virus patients with cirrhosis. Hepatology. 2012;56(2):532-543.

22. Welsch C, Efinger M, von Wagner M, et al. Ongoing liver inflammation in patients with chronic hepatitis $\mathrm{C}$ and sustained virological response. PLoS One. 2017;12(2):e0171755.

23. Ley B, Collard HR. Epidemiology of idiopathic pulmonary fibrosis. Clin Epidemiol. 2013;5:483-92.

24. Awadalla NJ, Hegazy A, Elmetwally RA. Occupational and Environmental Risk Factors for Idiopathic Pulmonary Fibrosis in Egypt: A Multicenter Case-Control Study. Int J Occup Environ Med. 2012;3(3):107-16.

25. Collard HR, Chen SY, Yeh WS, et al. Health Care Utilization and Costs of Idiopathic Pulmonary Fibrosis in U.S. Medicare Beneficiaries Aged 65 Years and Older. Ann Am Thorac Soc. 2015;12(7):981-987.

26. Fraser E, Hoyles RK. Therapeutic advances in idiopathic pulmonary fibrosis. Clin Med. 2016;16(1):42-51.

27. Northway WH, Rosan RC, Porter DY. Pulmonary disease following respirator therapy of hyaline-membrane disease. Bronchopulmonary dysplasia. N Engl J Med. 1967;276(7):357-68.

28. Payne MS, Goss KC, Connett GJ, et al. Molecular microbiological characterization of preterm neonates at risk of bronchopulmonary dysplasia. Pediatr Res. 2010;67(4):412-8.

29. Coalson JJ. Pathology of Bronchopulmonary Dysplasia. Semin Perinatol. 2006;30(4):179-184.

30. Ratner V, Slinko S, Utkina-Sosunova I, et al. Hypoxic stress exacerbates hyperoxia-induced lung injury in a neonatal mouse model of bronchopulmonary dysplasia. Neonatology. 2009;95(4):299-305.

31. Agrons GA, Courtney SE, Stocker JT, et al. Lung Disease in Premature Neonates: Radiologic-Pathologic Correlation1. Radio Graphics. 2005;25(4):1047-1073.

32. Bhandari A, Carroll C, Bhandari V. BPD Following Preterm Birth: A Model for Chronic Lung Disease and a Substrate for ARDS in Childhood. Front Pediatr. 2016;4:60.

33. Russell RB, Green NS, Steiner CA, et al. Cost of hospitalization for preterm and low birth weight infants in the United States. Pediatrics. 2007;120(1):e1-9. 
34. Smith VC, Zupancic JA, McCormick MC, et al. Trends in severe bronchopulmonary dysplasia rates between 1994 and 2002. J Pediatr. 2005;146(4):469-73.

35. Bhandari A, Bhandari V. "New" Bronchopulmonary Dysplasia. Clin Pulm Med. 2011;18(3):137-143.

36. Trembath A, Laughon MM. Predictors of Bronchopulmonary Dysplasia Clin Perinatol. 2012;39(3):585-601.

37. El Sayed M, Sherif L, Said RN, et al. Endothelin-1 and L-arginine in preterm infants with respiratory distress. Am J Perinatol. 2011;28(2):129 36.

38. Bhandari A, Panitch HB. Pulmonary outcomes in bronchopulmonary dysplasia. Semin Perinatol. 2006;30(4):219-26.

39. Anderson PJ, Doyle LW. Neurodevelopmental Outcome of Bronchopulmonary Dysplasia. Semin Perinatol. 2006;30(4):227-232.

40. Massey VL, Beier JI, Ritzenthaler JD, et al. Potential Role of the Gut/ Liver/Lung Axis in Alcohol-Induced Tissue Pathology. Biomolecules. 2015;5(4):2477-2503

41. Arteel GE. Oxidants and antioxidants in alcohol-induced liver disease Gastroenterology. 2003;124(3):778-790.

42. Guidot DM, Roman J. Chronic ethanol ingestion increases susceptibility to acute lung injury: role of oxidative stress and tissue remodeling. Chest. 2002;122(6 Suppl):S309-314.

43. Cox TR, Erler JT. Remodeling and homeostasis of the extracellula matrix: implications for fibrotic diseases and cancer. Dis Model Mech. 2011;4(2):165-78.

44. Zignego AL, Giannini C, Ferri C. Hepatitis C virus-related lymphoproliferative disorders: an overview. World J Gastroenterol. 2007;13(17):2467-78

45. Lok SS, Egan JJ. Viruses and idiopathic pulmonary fibrosis. Monaldi Arch chest Dis. 2000;55(2):146-50.

46. Irving WL, Day S, Johnston ID. Idiopathic pulmonary fibrosis and hepatitis C virus infection. Am Rev Respir Dis. 1993;148(6 Pt 1):1683-4.

47. Meliconi R, Andreone P, Fasano L, et al. Incidence of hepatitis C virus infection in Italian patients with idiopathic pulmonary fibrosis. Thorax. 1996;51(3):315-7.

48. Yamaguchi S, Kubo K, Fujimoto K ,et al., Analysis of bronchoalveolar lavage fluid in patients with chronic hepatitis $\mathrm{C}$ before and after treatment with interferon alpha. Thorax. 1997;52(1):33-7.

49. Aliannejad R, Ghanei M. Hepatitis C and pulmonary fibrosis. Hepat Mon. 2011;11(2):71-3.

50. Stefanova-Petrova DV, Tzvetanska AH, Naumova EJ. Chronic hepatitis C virus infection: prevalence of extrahepatic manifestations and association with cryoglobulinemia in Bulgarian patients. World $J$ Gastroenterol. 2007;13(48):6518-28

51. Ferri C, La Civita L, Fazzi P, et al. Interstitial lung fibrosis and rheumatic disorders in patients with hepatitis $\mathrm{C}$ virus infection. Br J Rheumatol. 1997;36(3):360-5.

52. Moriyama M, Arakawa Y. Treatment of interferon- $\alpha$ for chronic hepatitis C. Expert Opin Pharmacother. 2006;7(9):1163-1179.

53. Filippatos G, Tilak M, Pinillos H, et al. Regulation of apoptosis by angiotensin II in the heart and lungs (Review). Int $J$ Mol Med.2001;7(3):273-80.

54. Li X, Molina-Molina M, Abdul-Hafez A, et al. Angiotensin converting enzyme-2 is protective but downregulated in human and experimental lung fibrosis. Am J Physiol Lung Cell Mol Physiol. 2008;295(1):L178-85.
55. Osterreicher CH, Taura K, De Minicis S, et al. Angiotensin-convertingenzyme 2 inhibits liver fibrosis in mice. Hepatology. 2009;50(3):929938.

56. Jiang F, Yang J, Zhang Y, et al. Angiotensin-converting enzyme 2 and angiotensin 1-7: novel therapeutic targets. Nat Rev Cardiol. 2014;11(7):413-26

57. Li X, Zhang H, Soledad-Conrad V, et al. Bleomycin-induced apoptosis of alveolar epithelial cells requires angiotensin synthesis de novo. Am J Physiol Lung Cell Mol Physiol. 2003;284(3):L501-7.

58. Filippatos G, Uhal BD. Blockade of apoptosis by ACE inhibitors and angiotensin receptor antagonists. Curr Pharm Des. 2003;9(9):707-14.

59. Hale TM. Persistent phenotypic shift in cardiac fibroblasts: impact of transient renin angiotensin system inhibition. $\mathrm{J} \mathrm{Mol} \mathrm{Cell} \mathrm{Cardiol.}$ 2016;93:125-32.

60. Simões E Silva AC, Teixeira MM., ACE inhibition, ACE2 and angiotensin-(1-7) axis in kidney and cardiac inflammation and fibrosis. Pharmacol Res. 2016;107:154-62.

61. Uhal BD, Li X, Piasecki CC, et al. Angiotensin signalling in pulmonary fibrosis. Int J Biochem Cell Biol. 2012;44(3):465-8.

62. Uhal BD, Abdul-Hafez A. Angiotensin II in apoptotic lung injury: potential role in meconium aspiration syndrome. $J$ Perinatol. 2008:28 Suppl 3;S108-12.

63. Grace JA, Herath CB, Mak KY, et al. Update on new aspects of the renin-angiotensin system in liver disease: clinical implications and new therapeutic options. Clin Sci (Lond). 2012;123(4):225-39.

64. Goossens GH. The renin-angiotensin system in the pathophysiology of type 2 diabetes. Obes Facts. 2012;5(4):611-24.

65. Macconi D, Remuzzi G, Benigni A. Key fibrogenic mediators: old players. Renin-angiotensin system. Kidney Int Suppl. 2014;4(1):58-64.

66. Chappell MC. Biochemical evaluation of the renin-angiotensin system: the good, bad, and absolute? Am J Physiol Heart Circ Physiol. 2016;310(2):H137-52.

67. Flores-Muñoz M, Godinho BM, Almalik A, et al. Adenoviral Delivery of Angiotensin-(1-7) or Angiotensin-(1-9) Inhibits Cardiomyocyte Hypertrophy via the Mas or Angiotensin Type 2 Receptor. PLoS One. 2012;7(9):e45564.

68. Warner FJ, Lubel JS, McCaughan GW, et al. Liver fibrosis: a balance of ACEs? Clin Sci (Lond). 2007;113(3):109-18.

69. Gallagher PE, Chappell MC, Ferrario CM, et al. Distinct roles for ANG II and ANG-(1-7) in the regulation of angiotensin-converting enzyme 2 in rat astrocytes. Am J Physiol Cell Physiol. 2006;290(2):C420-6.

70. Uhal BD, Li X, Xue A, et al. Regulation of alveolar epithelial cell survival by the ACE-2 / angiotensin 1-7/ Mas axis. Am J Physiol. 2011;301(3):L269-274.

71. Abbas G, Silveira MG, Lindor KD. Hepatic fibrosis and the reninangiotensin system. Am J Ther. 2011;18(6):e202-8.

72. Mak KY, Chin R, Cunningham SC, et al. ACE2 Therapy Using Adenoassociated Viral Vector Inhibits Liver Fibrosis in Mice. Mol Ther. 2015;23(9):1434-43

73. Mohamed TL, Nguyen HT, Abdul-Hafez A et al. Prior hypoxia prevents downregulation of ACE-2 by hyperoxia in fetal human lung fibroblasts. Exp Lung Res. 2016;42(3):121-130.

74. Oarhe CI, Dang V, Dang M, et al. Hyperoxia downregulates angiotensinconverting enzyme-2 in human fetal lung fibroblasts. Pediatr Res. $2015 ; 77(5): 656-62$. 
75. Wagenaar GT, Laghmani el H, Fidder M, et al. Agonists of MAS oncogene and angiotensin II type 2 receptors attenuate cardiopulmonary disease in rats with neonatal hyperoxia-induced lung injury. Am J Physiol Lung Cell Mol Physiol. 2013;305(5):L341-L351.

76. Uhal BD. Cell cycle kinetics in the alveolar epithelium. Am J Physiol. 1997;272(6 Pt 1):L1031-45.

77. Barkauskas CE, Cronce MJ, Rackley CR, et al. Type 2 alveolar cells are stem cells in adult lung. J Clin Invest. 2013;123(7):3025-36.

78. Uhal BD, Dang M, Dang V, et al. Cell cycle dependence of ACE-2 explains downregulation in idiopathic pulmonary fibrosis. Eur Respir J. 2013;42(1):198-210.

79. Imai Y, Kuba K, Rao S, et al. Angiotensin-converting enzyme 2 protects from severe acute lung failure. Nature. 2005;436(7047):112-116.
80. Shenoy V, Ferreira AJ, Qi Y, et al. The Angiotensin-Converting Enzyme 2/Angiogenesis-(1-7)/Mas Axis Confers Cardiopulmonary Protection against Lung Fibrosis and Pulmonary Hypertension. Am J Respir Crit Care Med. 2010;182(8):1065-1072.

81. Jobe AH, Hillman N, Polglase G, et al. Injury and Inflammation from Resuscitation of the Preterm Infant. Neonatology. 2008;94(3):190-196.

82. Hillman NH, Gisslen T, Polglase GR, et al. Ventilation-induced increases in EGFR ligand mRNA are not altered by intra-amniotic LPS or ureaplasma in preterm lambs. PLoS One. 2014;9(4):e96087.

83. Khan A, Benthin C, Zeno B, et al. A pilot clinical trial of recombinant human angiotensin-converting enzyme 2 in acute respiratory distress syndrome. Crit Care. 2017;21(1):234. 